\title{
Opportunities and Challenges of Private Sector Driven Agricultural Innovations: The Case of Kenya Innovation Engine
}

\section{J. M. Machini*, Titianne Donde}

Land O'Lakes International Development, Block A, $2^{\text {nd }}$ Floor, Peponi Plaza, Off Peponi Road, Westlands, P.O. Box 45006 G.P.O. 00100, Nairobi, Kenya

\section{ABSTRACT}

Introduction: Persistent food insecurity in Africa partly stems from the limited capacity in most of the African countries to invest in existing and homegrown agricultural innovations with the potential to positively impact on household income, food security, and livelihoods. Many of such innovations which are nascent face challenges of poor infrastructure, limited legal support systems, insufficient human and financial capital. Regarding financial capital, the innovations are often times looking for funds to buy down risk and allow the innovators test their innovations and then scale them to greater market access and sustainability. Of these, the private sector driven agricultural innovations stand a good chance of impacting positively on food security, nutrition and poverty alleviation due to their inherent demand-driven focus which ensures sustainability. Methods: Between 2013 and 2015, Feed the Future Kenya Innovation Engine (KIE) a USAID funded program competitively solicited for private sector driven agricultural innovations from within Kenya, with a potential to positively impact on food security, nutrition and poverty and received 679 application over four separate calls for applications. After a rigorous review process of the applications, 20 innovations qualified for grant support. The selected innovations were awarded grants (which included cash support and short-term technical assistance) to implement for a period of 12-24 months, with possibility of follow on funding contingent to proof of capability to scale the businesses. Results and Discussion: This paper examines opportunities, and challenges of these private sector driven agricultural innovations, targeting improved food security and nutrition and poverty alleviation which if addressed will ensure successful growth of innovations to scale.

Key words: Food security, innovations, livelihoods, nutrition, poverty, private sector, sustainability

\section{INTRODUCTION}

By 2050 the sub-Saharan Africa population will have grown by about $114 \%^{[1]}$ thus requiring increased concerted efforts by state and non-state actors to ensure food security and improved household incomes. Food insecurity is partly due to limited access to appropriate agricultural innovations $^{[2]}$ and limited private sector involvement, ${ }^{[3]}$ which negatively impacts on food production, storage, distribution, and market access. Thus, farmers' capacity to access the innovations and requisite inputs needed to boost their capacity to produce and access markets are disabled.

This scenario is partly attributed to the unsustainable model of development organizations, which have a top-down support mechanism in terms of donations, prescribed agricultural solutions, and passive role of farmers. ${ }^{[4]}$ These

*Corresponding author:

Email: justin.mabeya@gmail.com

http://dx.doi.org/10.20530/IJIA429 have resulted in support systems that continuously crave for more support by both governments and farmers and hence collapse of many agricultural development projects once the support dries up. An impact of this is that Africa has incrementally been receiving food aid from the late $1950 s^{[5]}$ even though the food aid emergencies have since tripled alongside increased directed agricultural development aid. With more food insecurity and related crises, the situation in Africa is not any better now compared to 1950s despite an abundance of resources, including water and land. Elsewhere, the World Bank has reported that approximately $75 \%$ of African agricultural projects have been failures. ${ }^{[6]}$

More than $\$$ trillion in development assistance over the past several decades has not made African better but rather worse off, and it has helped make the poor poorer, and economic growth in the continent slower. ${ }^{[7]} \mathrm{A}$ number of factors contribute to low impact and sustainability of donor aid. These include deliberate diversion of donor funds by the recipient government to unintended use as was the case in Ethiopia where food aid was sold to finance the purchase of arms. ${ }^{[8]}$ Such aid may also be used to fund poorly informed and ill-structured government subsidy 
programs on agricultural inputs. A case in point is Zambia's input subsidy program, which led to the distortion of market prices and subsequent reduction in the availability of inputs and crop productivity. ${ }^{[9]}$ Zambia's programme did not target the poorest and most vulnerable households, it was state-driven and founded on a non-competitive delivery system.

To address this challenge, there have been efforts to mainstream private sector players into donor-funded agricultural development programs in a bid to enhance the sustainability of the programs on exit of the donor assistance. This is the framework on which the Feed the Future (FTF) Initiative of the US Government ${ }^{[10]}$ is based. This structure requires that the private sector is named as a priority partner and is considered critical to efforts geared toward reducing poverty, fighting hunger, and improving nutrition. The FTF initiative envisions an enabling environment and physical infrastructure that will facilitate private sector investment by individual agricultural producers, small and medium enterprises, and larger businesses. ${ }^{[11]}$ In Kenya, the FTF Initiative operates through a number of programs, one of which is the FTF Kenya Innovation Engine (KIE) a project that was initiated in 2012 and was scheduled to end in 2017.

KIE was designed to identify, foster and bring to scale innovative, private sector-oriented solutions that address food insecurity and persistent poverty, ${ }^{[12,13]}$ particularly across target populations within the FTF focus regions - High Rainfall Zone 1 and Semi-Arid Zone 2. Designed to mimic a venture capital structure ${ }^{[14]}$ KIE was largely groundbreaking on the Kenyan agricultural development landscape. Implemented by Land O'Lakes International Development, the innovation engine identified and nurtured 20 nascent agricultural innovations through a unique process. This new framework unearthed the wide spectrum of opportunities that lie unexploited in the Kenyan agricultural sector and the related challenges, which this paper shares.

\section{MATERIALS AND METHODS}

This review paper draws from the KIE reports, the authors' experiences as implementers of the KIE and published literature on the subject of agricultural innovations. KIE design mimics a venture capital arrangement, where identified innovations received grant funding including technical assistance to buy down risk and allow the nascent businesses grow to scale while being couched and nurtured through the process [Figure 1].

During the life of the project, KIE released a total of four rounds of requests for applications (RFA) from selected agricultural value chains - maize, dairy, horticulture as well as staple food crops such as sorghum and millet and received a total of 679 applications. In recognition of the possible wide diversity of innovations in terms of type, stage of innovation development, technical and financial need and source the KIE organized the innovation solicitation process in such a way that the applicants would be categorized according to their specific needs. The categories included "proof of concept" (Stage 1), "pilot rollout" (Stage 2), and "transition to scale" (Stage 3). This process led to approval for grant funding to 20 innovations (seven each from the first and second solicitations and six from the third and the fourth solicitations) [Appendix 1]. 16 of the innovations were at the proof of concept (Stage 1) and four at pilot rollout (Stage 2). The innovations' businesses cut across several categories including but not limited to pest control, information communication technology (ICT), post-harvest management, soil health, and market access. $\mathrm{KIE}$ provided the selected entrepreneurs (innovators) with early-stage capital for growth and expansion from underdeveloped or developing products and revenues. Further, KIE supported the innovators with technical assistance to build organizational capacity, partnerships with the public and private sector players for leverage so as to enhance business growth, publicity and couching

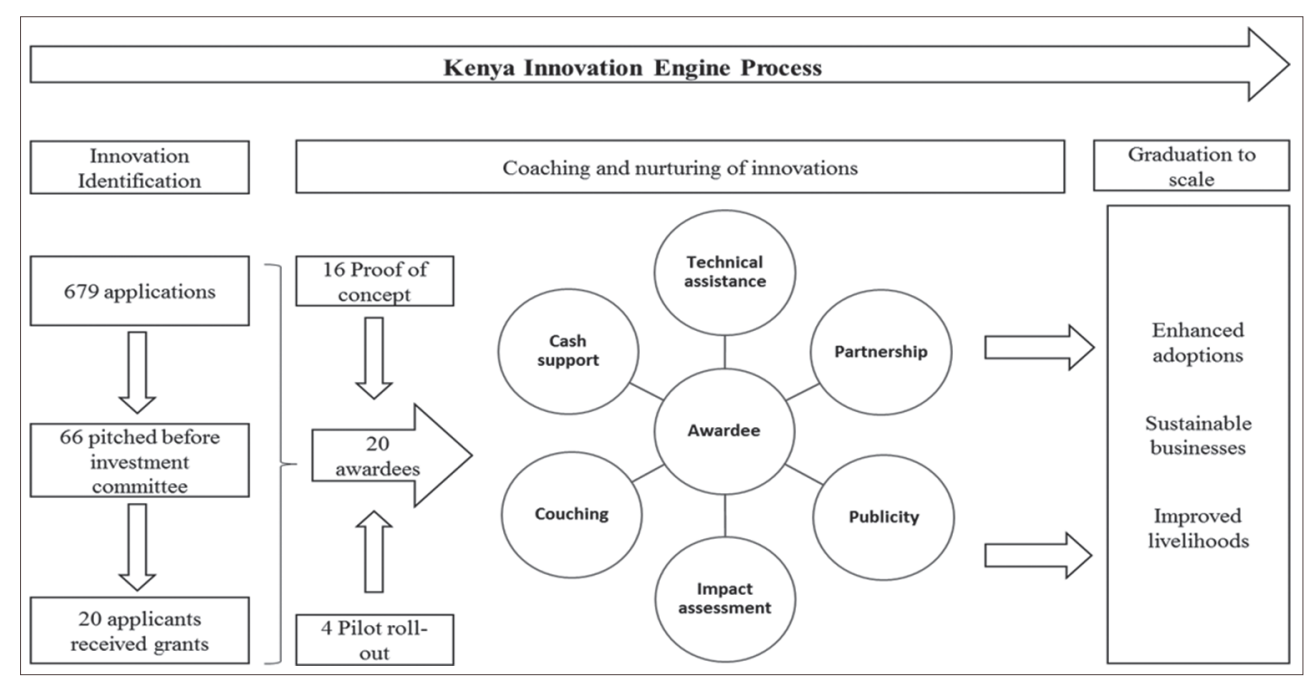

Figure 1: The Kenya innovation engine process 
(handholding) through innovation implementation process. Toward the end of the process, KIE assessed individual innovation to determine their impact and the extent to which the innovations are ready to transition to scale. Independent review was undertaken to verify outcomes and test reliability of results relevant to each stage (proof of concept or pilot rollout). The review process examined the innovation progress with regard to impact expectations for the innovation toward scaled market deployment. The whole process aimed at enabling the innovations to grow toward business sustainability where there is high product demand, a large customer base and improved livelihoods.

\section{RESULTS AND DISCUSSION}

The KIE pursued processes which were essentially untested in the Kenyan landscape. The KIE borrowed/adapted lessons from venture capital funds where innovative private sector strategies are incubated for growth to scale. ${ }^{[13]}$ Throughout the implementation process, KIE has identified several opportunities for success of nascent agricultural innovations and challenges which if addressed will ensure successful growth of innovations to scale.

\section{Opportunities for Development of Agricultural Innovations in Kenya}

Key opportunities identified include the large number of innovations available, willingness of the private sector to partner with the innovators, opportunities to support organizational development and business growth, public opportunities for sharing experiences of the innovators, and potential to impact positively on food security and household income.

In its solicitation process, KIE received 679 applications from three RFAs, a pointer to the great number of potential innovations available with the Kenyan landscape. This speaks to the need for regular science and innovation audits within the research and development organizations to continually unearth innovations and will provide evidence and mechanisms for investment decisions. ${ }^{[15]}$ Some of the winning innovations included: Crop varieties that are disease and pest resistant as well as drought tolerant; business development models that enhanced access to farm inputs through collaborative ventures with agro-dealers and other service providers for improved crop productivity and reduction of transaction costs; "Last-mile" extension services that enable the very poor to access information, knowledge, and markets. Others were application of ICT to disseminate agricultural information more efficiently; microfinancing infrastructure; fresh produce storage methods and facilities, irrigation, processing and/or packaging technologies; contract farming and mechanization and; facilitation of public-private investments in the animal feed industry, and value-added opportunities in regional markets.

A number of innovations whether at production, distribution and marketing of produce or input distribution managed to attract a growing private sector involvement and support along the value chain which was valued at more than $\$ 4.2$ million by the end of June 2017. For example, Kenya Biologics attracted equity investment into the business from a European company to grow its biopesticides business, and iProcure received equity support to provide digital financial and non-financial services to support the increase of smallholder farmers' agricultural productivity, profitability, income, and savings. Overall, 15 out of 20 enterprises received private sector funding to support the development of their enterprises.

Other than financial support, the KIE innovations benefitted from private sector partners' organizational strengths. The partnerships helped innovations to establish sustainable and scalable organizational models to meet program goals. One example is that of Arid Lands Information Network (ALIN) which partnered with Times U SACCO Ltd in Meru County, where the SACCO used farmer data from ALIN to avail loans to smallholder farmers. At the same time, ALIN partnered with Farmers Centre Ltd in Meru town to facilitate soil testing for the Farmers at the Centre. Another example is partnership signed among iProcure, Safaricom and NovaStar to implement the Digifarm project, which is focused on providing digital financial and non-financial services to increase farmer productivity, profitability, income, and savings. Another innovator Kenya Medical Research Institute (KEMRI), partnered with Villgro Kenya to benefit from business incubation by Villgro Kenya, an impact investment company for global health innovations. This dynamic interaction and engagement with private sector partners fitted into the thinking of agricultural innovation systems (AIS), which encourages the involvement of several actors to take advantage of the several perspectives and skills which they represent ${ }^{[16]}$ which also provides an exit strategy for innovations once the KIE support ran out. These arrangements are consistent with the innovations systems thinking contemplated in the innovations development process for enhancing organizational performance. ${ }^{[17]}$ Use of innovation systems thinking implies that the process should embrace the use of innovation as the lens "in the design, implementation, and evaluation of the activities of the various actors involved in the innovation process." ${ }^{[17,18]}$ This involves analysis of (a) the components of the system, principally its actors; (b) the relationships and interactions between the actors; and (c) the competencies, functions, process, and results generated through the interactions 
of the actors. As observed, active engagement among the innovators and other private sector players enhanced organizational capacity and impact of the innovation. Leveraging private sector businesses offers the innovators a variety of products and services that can contribute to improved food security. The private companies can support access to improved technologies, increased product quality, finance, and markets thus contributing to enhanced business and higher profitability. ${ }^{[19]}$

Typically early-stage innovations encounter monumental challenges related to resources mobilization to support the growth of the business. The innovation engine's structure of a venture capital-like entity was able to identify several entities (local and international) which would provide funding along the lines of grants, equity, and debt. The innovation linked innovators with business forums which provided opportunities to network with the-would-be funders to enable ease of access to funding. Examples of business forums include Sankalp Forum, Aspen Network of Development Entrepreneurs (ANDE), and Kenya Climate Innovation Center ( $\mathrm{KCIC})$. Intellecap organizes Sankalp Africa Summits for global, inclusive development dialogs with entrepreneurs, impact investors, corporates, and governments ${ }^{[20]}$ ANDE is a global network of organizations that propel entrepreneurship in emerging markets. ANDE members provide critical financial, educational, and business support services to small and growing businesses (SGBs) based on the conviction that SGBs will create jobs and stimulate business growth and development. $\mathrm{KCIC}$ agribusiness component "aims to support enterprises developing innovative agricultural technologies that make such changes possible, and which in turn improve the efficiency of small-scale farms." ${ }^{\text {[21] }}$ The innovators were also linked with venture capital funds including Root Capital, Africa Enterprise Challenge Fund, and the Village Capital. It has been established that private equity investment could help create, deepen, and expand the growth of small and medium enterprises in developing economies. $^{[22]}$

Early stage innovators lack capacity to reach out to the public and tell the story about the value of their innovations. In essence, organizations looking for innovations in the Kenyan landscapes would require significant efforts and time to determine the existence and location of the innovations in the absence of an innovation audit. The KIE provided a number of opportunities to these nascent technologies to showcase to large audiences. Two awardees - University of Nairobi and Virtual City Ltd had the opportunity of speaking at the 2014 TEDx Nairobi, to a 700 strong audience. Other international exposure opportunities were the 2015 Global Entrepreneurship Summit held in Nairobi, the Amsterdam Impact Week, the Africa Food Security Conference, the African Dairy
Conference and Exhibition (AfDA - formerly known as ESADA) and the Nairobi Innovation Week. In addition, KIE released monthly "The Innovator" an e-bulletin, dedicated to technology, creativity, innovation and how they are impacting lives of Kenyans. The e-bulletin reached over 600 subscribers including USAID and other development partners, local and international innovators, potential investors, media as well as other agricultural and enterprise development program implementers in Kenya and across Africa. It has been established that such opportunities for publicity broaden the avenues for market expansion and possibilities of accessing necessary technical assistance to innovators. ${ }^{[23]}$

The KIE was developed and structured with the objective of positively impacting the smallholder farmers with regard to poverty reduction, improved food security and nutrition. Over time the implementing innovations showed impact with regard to the number of farmers who continued to benefit from the innovations. For example, by the end of June 2017 over 120,000 farmers had adopted the 20 different innovations which adoptions are positively impacting their livelihoods in terms of improved production, market access, financial inclusion, and so on. This finding is consistent with the results from a study by Adebayo and Olagunju, ${ }^{[24]}$ which concluded that agricultural research interventions that are driven by AIS concepts have the potential to positively impact the livelihoods of rural smallholder farmers. In addition, AIS concepts should be mainstreamed in all public agricultural extension and research programs to ensure sustained rural innovation and robust livelihood and improved productivity outcomes. ${ }^{[24]}$

\section{Challenges in Managing Agricultural Innovations}

The KIE experienced a number of challenges including delays in implementation caused by operational difficulties, staff turnover, prolonged government regulatory approval processes, failure of innovators to implement sound technical practices in the field, lack of flexibility on the program and the innovators to adjust the innovations as necessary and delayed USAID approval processes.

At the onset of implementation of the innovations, a number of award recipients experienced timing delays in getting their field activities underway and in some cases halting of the activities mid-way through the implementation. This was due to a host of operational challenges, including prolonged engagement with prospective partner farmers to secure their buy-in and participation. Initial delays in identification of readily available technical assistance service providers and negotiation of appropriate remuneration was another challenge. The need to mitigate the mismatch of 
agricultural cycles and award cycles also caused some delays. An example of the operational challenge was the complete randomized trials for impact evaluation for the Lachlan Kenya's Viazi Power pilot rollout project, which was planned for but later determined to be unnecessary and of no value for a private company business. Ultimately these delays necessitated no-cost extensions by an additional 3-6 months for 10 innovations: Lachlan East Africa Ltd., Wanda Organic, MFarm, Maseno University, University on Nairobi - 2, KEMRI, Caytree Partners Limited, Kenya Biologics Ltd and Dissemination of Agricultural Technologies (KENDAT), and University of Nairobi 1. As a measure of ensuring quick traction of the innovation implementation, the Innovation Engine put in place appropriate remedial measures for execution readiness for incoming projects to ensure no time loss while minimizing cost overruns.

Typical of the project based implementation, KIE's 5-year lifespan did not provide long enough opportunities for staff to dissuade them from signing onto new compelling opportunities. As a result, a number of staff left employment at the Innovation Engine and this presented implementation challenges. By the end of June 2017, a total of eight key personnel staff cutting across finance, monitoring and evaluation, grants management and technical had left the Innovation Engine. These departures led to the KIE lagging behind in some contractual obligations like reporting as a result of delays inflow of information from the field and its subsequent compilation.

Innovations for crop nutrition (e.g., Wanda Organic Plantmate fertilizer) and pest control (e.g., Real IPM's biological control of fruit fly) required regulatory approval by the Ministry of Agriculture and Pest Control Products Board (PCPB), respectively, before they could be allowed for commercialization. For such innovations even with successful proof of concept (Stage 1) implementation, recommendation for stage progression to pilot rollout (Stage 2) was delayed. For example, further activities for the Real IPM's Real Metarhizium for fruit fly control were stalled by lack of specific regulatory approvals from PCPB. The innovations that received such statutory approvals, for example, Wanda Organic for Plantmate and Prime EC fertilizers and Kenya Biologics for its Tutrack insect trap, proceeded to Stage 2 implementation.

A number of innovators by either omission or commission failed to implement recommended agronomic and business practices leading to poor performance of their innovations. Examples include those of MFARM, Virtual City, and Lachlan East Africa. Beans produced by farmers contracted by MFARM were sometimes collected late or never collected at all, thus resulting in losses. These challenges at farm level discouraged many farmers resulting in their discontinuation of the partnership with MFARM. For Virtual city, some of the partner farmers had disease management challenges which were not addressed on time by the innovator. Further, Virtual City had insufficient storage space for harvested produce, which led to the loss of almost half of the harvest leading to poor returns to the farmers. In some instances for Lachlan, sufficient agronomic practices such as proper crop variety selection and proper management of soil conditions were not being applied, which resulted in poor production. All these short-comings served to disenfranchise the farmers leading to poor adoption and impact of the respective innovations.

Innovation success is hinged on a progressive iterative process of testing and refining with the view of improving on the innovation and ensuring increased impact. For some of the innovations, the champions exhibited deliberate rigidity to iterate progressively leading to failure to progress to the next stage. For example, MFARM lacked the necessary agility not only to be knowledgeable about software linking farmers to market but also to build agricultural technical capacity and understand their customers. The biggest stumbling block was that MFARM was unable to build trust among its customers - the farmers using their software products. Similarly, Virtual City's AgriManager innovation (portable electronic scale tied to mobile phone software) focused at reducing fraud between the farm gate and the aggregator by tracking the quantity of produce and automating the supply chain. This assumption proved erroneous as the principal issue facing the horticulture value chain in Kenya in relation to the market for the fresh produce is traceability which was not being addressed by the innovation.

Implementation of individual innovations was contingent to approval by USAID of the qualified applications. This approval process was often times protracted and delayed. For example, though Land O'Lakes entered into a contract to implement the Innovation Engine in 2012, implementation of the first cohort of awardees did not start until 2014 partly due to the delay on the part of USAID to expedite necessary approvals. These delays were witnessed at every stage of innovations approvals, the latest being the approval for implementation of Stage 2 innovations (Value Farms, Indicus Ltd., and Takaful Insurance) by the Innovation Engine which lagged behind by 1 year relative to other innovations in the cohort (Kenya Biologics, KENDAT and Caytree Partners) implementing at Stage 1.

\section{CONCLUSION}

Agricultural innovation implementation success is juxtaposed between seizing available opportunities and implementing an effective coaching and nurturing 
program, which recognizes that hiccups are part of the iterative process for growing nascent businesses. KIE identified and nurtured several agricultural innovations through a replicable process typical of a learning curve for both the innovators and KIE. It is evident that there exist untapped latent agricultural innovations in the Kenyan landscape which if identified and supported to grow as businesses could contribute to improved livelihoods among smallholder farmers and enhanced economy. Increased efforts through technology and innovation audit would help in unearthing this potential.

Nascent innovations require capacity building through training, coaching and partnerships with private sector players to grow them into vibrant, sustainable businesses. Early stage innovations require technical assistance in building businesses, market linkages, financial assistance to buy down risks and build their capital and hand-holding to navigate through any challenges and ensure growth to business scale. KIE managed to do this during its project life. For sustainability of this innovation stream, there is a need for a structured government system that taps into the innovations and links them with support systems (with public and private sector players) which facilitate their growth sustainable businesses.

\section{REFERENCES}

1. FAO. Global Agriculture Towards 2050, How to feed the World 2050. High Level Expert Forum. Rome: FAO; 2009.

2. Asfaw S, Battista FD, Lipper L. Food Security Impact of Agricultural Technology Adoption Under Climate Change: Micro-Evidence from Niger. ESA Working Paper No. 14-12 December 2014 Agricultural Development Economics Division Food and Agriculture Organization of the United Nations; 2014. Available from: http//www.fao. org/economic/es1a.

3. Tuttle FN. Private Sector Engagement in Food Security and Agricultural Development. Centre for Strategic International Development; 2012. Available from: http://www.csisprod.s3.amazonaws.com/s3fs-public/legacy_files/files/ publication/120329_Nesseth_PrivateSector_web.pdf.

4. Taye H. Evaluating the impact of agricultural extension programmers in sub-Saharan Africa: Challenges and prospects. Afr Eval J 2013. Available from: http://www. aejonline.org/index.php/aej/article/view/19/36.

5. United Nations Economic Commission for Africa. Assessing Progress in Africa toward the Millennium Development Goals, MDG Report 2013: Food security in Africa: Issues, Challenges and Lessons; 2013.

6. Hancock G. The Lords of Poverty. New York: Atlantic Monthly Press; 1989. p. 145.

7. Moyo D, Aid D. Why Aid is not Working and how there is a Better Way for Africa. London, England: Penguin Books Ltd, Registered Offices: 80 Strand; 2009.

8. Plaut M. Ethiopia Famine Aid 'Spent on Weapons'. Africa editor. BBC World Service. Available from: http://www. news.bbc.co.uk/1/hi/8535189.stm.

9. Baltzer K, Hansen H. Evaluation Study: Agricultural input subsidies in Sub-Saharan Africa. Frederiksberg: Institute of Food and Resource Economics, University of Copenhagen Rolighedsvej; 2012.

10. Lawson ML, Schnepf R, Cook N. The Obama Administration's Feed the Future Initiative. US Congressional Research Service 7-5700; 2016. Available from: http//www.crs.gov.

11. Feed the Future. Feed the Future, the US Government's Global Hunger and Food Security Initiative; 2017. Available from: https://www.feedthefuture.gov.

12. Kenya Feed the Future Innovation Engine. Feed the Future Kenya Innovation Engine, part of US Government's Global Hunger and Food Security Initiative; 2017. Available from: http://www.kfie.net.

13. Land O'Lakes International Development. Land O'Lakes International Development, Technical Proposal for Kenya Feed the Future Innovation Engine, Requests for Application by USAID East Africa. Land O'Lakes; 2012. Available from: http://www.pdf.usaid.gov/pdf_docs/PA00MTJJ.pdf. [Last accessed on 2017 Oct 15].

14. Bogliacino F, Lucchese M. Access to Finance for Innovation: The role of Venture Capital and the Stock Market. IPTS Working Paper on Corporate R\&D and Innovation-No. 5; 2011.

15. Liao Y, Fan Y, Xi Y. A technological innovation management based on the audit. Int Bus Res 2011;4. Available from: http//www.ccsenet.org/ibr.

16. World Bank. Agricultural Innovation Systems, an Investment Sourcebook. International Bank for Reconstruction and Development/International Development Association or the World Bank; 2012. Available from: http//www. worldbank.org.

17. Anandajayasekeram P. The Role of Agricultural R\&D within the Agricultural Innovation Systems Framework. Paper Presented at the Agriculture R\&D: Investing in Africa's Future; ASTI/IFPRI-FARA Conference; 2011.

18. Banson KE, Nguyen NC, Bosch OJ, Nguyen TV. A Systems Thinking Approach to Address the Complexity of Agribusiness for Sustzainable Development in Africa. Australia: Systems Design and Complexity Management, University of Adelaide Business School, SA; 2014. p. 5005.

19. Hebebrand C. Leveraging Private Sector Investment in Developing Country Agrifood Systems, Study Commissioned by the Global Agricultural Development Initiative. Chicago, Illinos: The Chicago Council on Global Affairs; 2011.

20. Forum S. Sanklap Africa Summit; 2017. Available from: http://www.sankalpforum.com.

21. Kenya Climate Change Centre. Kenya Climate Change Centre; 2017. Available from: https://www.kenyacic.org.

22. Shanthi S, Masood S, Patrick JM. Private Equity and Venture Capital in Smes in Developing Countries: The Role for Technical Assistance (April 1, 2014). Washington, DC: World Bank Policy Research Working Paper No 6827. Available from: https://www.ssrn.com/abstract=2419273.

23. FAO/INRA. In: Loconto A, Poisot AS, Santacoloma P, editors Innovative Markets for Sustainable Agriculture-How Innovations in Market Institutions Encourage Sustainable Agriculture in Developing Countries. Rome, Italy: Food And Agriculture Organization of the United Nations (FAO), Institut National de la Recherche Agronomique (INRA); 2016.

24. Adebayo O, Olagunju K. Impact of Agricultural Innovation on Improved Livelihood and Productivity Outcomes among Smallholder Farmers in Rural Nigeria. Working Paper No. 2015/07. Maastricht School of Management; 2015 


\section{APPENDIX}

Appendix 1: The Kenya innovation engine innovations

\begin{tabular}{|c|c|c|c|c|}
\hline Round & No. & Grantee & Innovation & Stage \\
\hline \multirow[t]{7}{*}{1} & 1. & Lachlan East Africa Ltd & Viazi Power - Fusion Farming & 2 \\
\hline & 2. & Quest Agriculture & $\begin{array}{l}\text { Innovative and Inclusive Training and Extension Services for } \\
\text { Sustainable Production of Safe Food in Kenya (INTENSE) }\end{array}$ & 1 \\
\hline & 3. & Wanda Organic & $\begin{array}{l}\text { Participatory market evaluation of the efficacy of Plantmate } \\
\text { organic fertilizer and prime EC foliar plant food for smallholder } \\
\text { farmers }\end{array}$ & 1 \\
\hline & 4. & Real IPM & Biological control of fruit fly & 1 \\
\hline & 5. & MFarm & $\begin{array}{l}\text { Using mobile technology to link smallholder farmers to } \\
\text { horticulture markets }\end{array}$ & 1 \\
\hline & 6. & Virtual City & $\begin{array}{l}\text { Using mobile technology to increase transparency along the } \\
\text { horticulture value chain }\end{array}$ & 1 \\
\hline & 7. & University of Nairobi 1 & $\begin{array}{l}\text { Cooling Option for Smallholder Horticultural Farmers in } \\
\text { Kenya - CoolBot }\end{array}$ & 1 \\
\hline \multirow[t]{7}{*}{2} & 8. & Kenya Livestock Marketing Council (KLMC) & $\begin{array}{l}\text { Strengthening the dry land economy for pastoralist } \\
\text { communities through livestock identification and traceability } \\
\text { mechanisms }\end{array}$ & 1 \\
\hline & 9. & Amtech Technologies & Scaling up EASYMA for Dairy Farming Sustainability & 1 \\
\hline & 10. & Maseno University & $\begin{array}{l}\text { Enhancing Capacity of Maseno University Seed Unit to Deliver } \\
\text { to Market Resilient New Maize Varieties in Western Kenya }\end{array}$ & 1 \\
\hline & 11. & University on Nairobi - 2 & $\begin{array}{l}\text { Low-cost Optical Sorting to Remove Mycotoxins from Maize in } \\
\text { Local Kenyan Mills }\end{array}$ & 1 \\
\hline & 12. & Arid Lands Information Network (ALIN)/Sokopepe Ltd & $\begin{array}{l}\text { Farmer Records Management Information System (FARMIS) } \\
\text { that facilitates improved farmer record keeping }\end{array}$ & 1 \\
\hline & 13. & Kenya Medical Research Institute (KEMRI) & $\begin{array}{l}\text { Design and Clinical Evaluation of a School Meal with } \\
\text { Deworming Properties }\end{array}$ & 1 \\
\hline & 14. & iProcure & Last Mile Distribution of Farming Inputs & 1 \\
\hline \multirow[t]{6}{*}{3 and 4} & 15. & Caytree Partners Limited & Caytree Financial Empowerment and Loan Assistance Program & 1 \\
\hline & 16. & Kenya Biologics Ltd & Combating Tuta absoluta in tomatoes for smallholder farmers & 1 \\
\hline & 17. & $\begin{array}{l}\text { Kenya Network for Dissemination of Agricultural } \\
\text { Technologies (KENDAT) }\end{array}$ & $\begin{array}{l}\text { Agricultural Mechanization Hubs to Boost Youth-Attractive } \\
\text { Commercial Farming Ventures }\end{array}$ & 1 \\
\hline & 18. & Indicus EA Ltd & $\begin{array}{l}\text { Establishment of a high tech artificial insemination training } \\
\text { center }\end{array}$ & 2 \\
\hline & 19. & Value Farms Ltd & $\begin{array}{l}\text { Shifting the Paradigm on Land Consolidation through } \\
\text { Public-Private Partnership for Commercial Agriculture }\end{array}$ & 2 \\
\hline & 20. & Takaful Insurance of Africa & Index-based livestock insurance & 2 \\
\hline
\end{tabular}

